\title{
ANTI-INFLAMMATION: FINDING A NEW ROLE FOR HEAT SHOCK PROTEINS IN HUMAN HEALTH
}

\author{
YU CHEN * AND R. WILLIAM CURRIE \\ Department of Anatomy \& Neurobiology, \\ Sir Charles Tupper Medical Building, Dalhousie University, \\ 5850 College Street, Halifax, Nova Scotia, Canada B3H 1 X5
}

\begin{abstract}
Heat shock proteins (Hsps) are highly conserved proteins and have been proven to protect prokaryotic and eukaryotic cells in most organisms against external stressors, whether environmental or pathophysiological. This defense mechanism probably depends on the roles of Hsps as molecular chaperones in governing proper protein assembly, folding and transport or as anti-apoptotic regulators of cell death pathways. Recent investigations on human inflammatory diseases indicate that Hsps may be involved in the process of inflammation. In this short review, we describe the general concept of heat shock proteins and inflammation and the new anti-inflammation role of heat shock proteins in various inflammatory diseases such as infection, autoimmune diseases, ischemia/reperfusion injury, cardiovascular diseases and chemical-induced diseases. The Hsps may act as autoantigens to stimulate the immune system and interact with inflammatory intracellular signaling pathways to regulate the inflammatory response. There are still unanswered questions about the heat shock response that require further investigation.
\end{abstract}

Les protéines de choc thermique (Hsps) sont des protéines hautement conservées qui protègent les cellules de la plupart des organismes procaryotes et eucaryotes contre les facteurs de stress externes, que ceux-ci soient d'origine environnementale ou pathophysiologique. Ce mécanisme de défense est probablement lié au rôle de molécule chaperonne des Hsps qui interviennent dans l'assemblage, le repliement et le transport des protéines ou qui agissent comme agents anti-apoptotiques (régulation de la mort cellulaire). Des recherches récentes sur les maladies inflammatoires humaines indiquent que les Hsps peuvent intervenir dans le processus d'inflammation. Dans le cadre de ce court résumé, nous décrivons le concept général de protéines de choc thermique et de l'inflammation ainsi que le nouveau rôle anti-inflammatoire des protéines de choc thermique dans diverses maladies inflammatoires telles que les infections, les maladies autoimmunes, les lésions d'ischémie/reperfusion, les maladies cardiovasculaires et les maladies d'origine chimique. Les Hsps peuvent agir à titre d'autoantigènes qui stimulent le système immunitaire et interviennent dans les voies de signalisation intracellulaire en cas d'inflammation pour réguler la réaction inflammatoire. Les questions qui restent toujours sans réponse à propos de la réaction au choc thermique doivent faire l'objet de recherches plus poussées.

\section{HEAT SHOCK PROTEINS}

More than forty years ago Ferruccio Ritossa (1962) made the first observation that elevated temperatures could trigger rapid and specific 
changes in chromosomal and metabolic activity in Drosophila salivary gland cells producing a "puffing" of chromosomes. Ritossa concluded that the new puffs were indicative of novel gene expression. Twelve years later, Tissieres et al. (1974) showed that, indeed, novel proteins were expressed in cells after brief elevation of temperature. These initial findings lead to the discovery of a large number of stress (heat shock) proteins in many prokaryotic and eukaryotic organisms, tissues, individual cells and subcellular structures. Although heat shock proteins (Hsps) may have different names according to species in which they have been discovered, their nucleotide and amino acid sequence are highly conserved. Based on their related functions and size, the Hsps are grouped into several families: the $110 \mathrm{kDa} H \mathrm{sps}$, the $90 \mathrm{kDa} \mathrm{Hsps}$, the $70 \mathrm{kDa}$ Hsps, the $60 \mathrm{kDa} H s p s$, small Hsps such as Hsp27 and ubiquitin (Currie \& Plumier 1998). Hsp genes are regulated by heat shock transcription factors (HSFs). Under resting conditions, HSFs bind with Hsps in cytoplasm and are inactive. Under stressful conditions, Hsps are recruited to damaged or denatured proteins, leaving monomer HSFs free in the cytoplasm. HSF. is activated through a multi-step process, involving its phosphorylation by protein kinases such as protein kinase $C(P K C)$, its trimerization and its translocation to the nucleus where it binds to the heat shock element (HSE) in the promoter region of Hsp genes and initiates transcription. Hsp mRNA is transcribed and leaves the nucleus for the cytoplasm where new Hsps are synthesized.

All living organisms respond to a wide variety of stresses such as heat shock (HS), heavy metals, ischemia, sodium arsenite, microbial infections, nitric oxide, and antibiotics by synthesizing Hsps. Hsps are present in cytoplasm, mitochondria, endoplasmic reticulum and nuclei. Some Hsps are constitutively expressed at high levels (eg, Hsp90, Hsc70), whereas other Hsps are rapidly inducible to high levels in response to cellular stress (eg, Hsp70, Hsp27). Hsps primarily function as molecular chaperones and facilitate the refolding, assembling and stabilization of denatured proteins (Hartl 1996, Rogalla et al. 1999). Molecular chaperones have been defined as a class of proteins that mediate the correct folding of other proteins, but do not take part in the final assembly of the new structures (Ellis \& van der Vies 1991). Hsp chaperoning activity occurs in both nonstressed and stressed conditions, and maintains cytoskeletal function and cellular homeostasis. In addition, several Hsps have anti-apoptotic roles, regulating the activity of caspases, c-Jun $\mathrm{NH}_{2}$-terminal kinase (JNK), and the nuclear factor $\kappa \mathrm{B}$

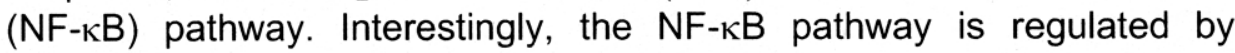
inflammation and it is also regulating the inflammatory response (Beere 2001, Polla et al. 1998). This may provide the missing link between the heat shock proteins and inflammation. Here, we review the roles of Hsps in various inflammatory diseases and propose a new role for Hsps in regulating inflammation. 


\section{INFLAMMATION: PHYSIOLOGICAL AND PATHOLOGICAL}

Inflammation is defined as "a fundamental, stereotyped complex of cytologic and chemical reactions that occur in affected blood vessels and adjacent tissues in response to an injury or abnormal stimulation caused by a physical, chemical, or biologic agent" in Stedman's concise medical dictionary (Dirckx 2001). The inflammatory response is triggered whenever body tissues are injured, whether by infectious agents (bacteria, virus, parasites), physical agents (burns, trauma, radiation), chemical agents (toxins, heavy metals, reactive oxygen species (ROS)), immunological agents such as certain antigens causing allergy and autoimmunity, or any other phenomenon, and it is essentially a vascular reaction. The main purpose of inflammation is the quick death and clearance of foreign pathogen or antigen as well as injury repair. The immune system is responsible for regulating inflammation by producing substances such as histamines, prostaglandins, cytokines, chemokines, and adhesion molecules. Cell types such as neutrophils, eosinophils, basophils, lymphocytes, macrophages, and mast cells and platelets are involved in the inflammatory process, releasing specific inflammatory mediators and initiating the intricate chemical cascade. In the early phase of inflammation, pro-inflammatory mediators cause a marked increase in vascular permeability, local blood flow, and cellular infiltration into the injured site. This early process is hallmarked by five cardinal signs: redness, swelling, heat, pain and loss of function. In the late phase of inflammation, mediators contribute to angiogenesis, tissue remodeling and regeneration, connective tissue formation; wound healing, phagocytosis, and apoptosis. While we often attempt to regulate or suppress inflammation, it is an essential physiological process, which begins following a sub-lethal injury and ends with complete healing (Florey 1970).

Under normal conditions, the inflammatory process is turned off as soon as possible to avoid its deleterious effects. Mechanisms involve activation of regulatory $T$ cells and secretion of anti-inflammatory cytokines in the late phase of inflammation, helping the organism to suppress the process. CD4+ $T$ cell can be divided into at least two different subsets that counterbalance each other (Mosmann \& Sad 1996). T-helper type 1 (Th1) lymphocytes are the most prevalent type of CD4+ $\mathrm{T}$ cells, and they promote inflammation by activation of macrophages and production of pro-inflammatory cytokines such as interleukin (IL)-2, IL-6, IL-8, tumour necrosis factor (TNF)- $\alpha$, and interferon (IFN) $-\gamma$. Counteracting the Th1 cells, the Th2 cells suppress inflammation and dampen macrophage activity by producing antiinflammatory cytokines, IL-5, IL-10, and IL-13. To maintain body homeostasis, the immune system has to diagnose the need for inflammation, control the exact mix of inflammatory molecules, and regulate the process spatially, often at multiple sites, temporally and in 
magnitude depending on the injury. If the inflammatory process is inappropriately regulated, spatially, temporally, or in magnitude of response, or fails to terminate, then the inflammation response itself can be pathological and become the cause of significant damage (Cohen \& Efroni 2003). Severe infection such as sepsis and non-infectious systemic inflammation response syndrome (SIRS; eg, surgery, trauma, burns, cardiac arrest and resuscitation, acute allograft rejection, etc) can cause acute and over-activated inflammatory response. Sustained inappropriate inflammatory response causes chronic inflammation and plays a role in autoimmune diseases such as type 1 diabetes, rheumatoid arthritis and atherosclerosis (Wick et al. 2001). Pathological inflammation is a feature of many diseases and the regulation of the inflammatory response and the suppression of pathological inflammation is the focus of extensive research efforts.

\section{HSPS PROTECT AGAINST INFLAMMATORY DISEASES}

\section{Infection diseases}

Infection represents a stress for both the host and the pathogen. The host cell stress response is differentially regulated according to the type of infected cell and the type of pathogen, the microenvironment and the specific intercellular or intracellular communication (Polla et al. 1998). Pathogen toxins damage the host by triggering inappropriate inflammation, and the host is made sick by its own inflammatory reaction to pathogenic stimuli that trigger TNF- $\alpha$, IFN- $\gamma$ and other proinflammatory mediators (Calandra et al. 2002). Hsps are involved in cytoprotection against various pathogen infections. Hsp70 protects macrophages infected with Salmonella choleraesuis against TNF- $\alpha$ induced cell death and induces immunoregulatory CD4+ T cells during the course of infection with Listeria monocytogenes (Yoshikai 1998). Hsp70 also protects rat pancreas from Cerulein-induced pancreatitis-like injury (Bhagat et al. 2000). Over-expression of Hsp70 inhibits bacterial lipopolysaccharide (LPS)-induced production of cytokines in human monocyte-derived macrophages, LPS-induced lung inflammation, septic shock and accelerates mouse recovery after endotoxic challenge (Ding et al. 2001, Vreugdenhil et al. 2003, Eaves-Pyles et al. 2000, Paidas et al. 2002). In addition, HSF-1 deficient (HSF-/-) mice produced greater amounts of pro-inflammatory cytokines and were more susceptible to endotoxin-mediated lethality compared with wild-type mice (Xiao et al. 1999). During viral infection, elevated Hsps inhibit specific events in the viral cycle leading to inhibition of viral replication (Santoro 1994), and in fact, Hsp70 may be the cellular mediator interfering with viral protein synthesis (Santoro 1997). Sodium arsenite, cadmium, azetidine, and HS, all induce the expression of Hsps and inhibit the synthesis of Sendai virus protein synthesis as long as Hsp synthesis is occurring in the 
infected human cells (Santoro 1997).

\section{Autoimmune diseases}

Autoimmune diseases are the classic example of inappropriate inflammation. Recent experiments in the adjuvant-induced arthritis (AIA) rat model of rheumatoid arthritis (RA) have shown promising results using Hsp peptides to suppress the inflammatory injury. Nasal administration of Hsp60 180-188 peptides induces highly effective protection against AIA through generation of regulatory $\mathrm{T}$ cells that produce anti-inflammatory cytokines such as IL-4, TGF- $\beta$ and mainly IL10 (Prakken et al. 2002, 2003). Mycobacterial Hsp10 (Agnello et al. 2002) and Hsp70 (Wendling et al. 2000) have also been found to suppress AIA. A phase I clinical trial was performed treating early RA patients with dnaJp1 peptide derived from the E. coli Hsp (Puga Yung et al. 2003). Interestingly, oral treatment with dnaJp1 reduces the $T$ cell proliferative response, IL-2, IFN- $\gamma$ and TNF- $\alpha$, and stimulates the T cells to produce IL-4 and replaces the majority of TNF- $\alpha$-producing cells with $\mathrm{IL}-10$ and IL-4 producing cells. Such treatment with dnaJp1 suggests that Hsps or peptides derived from Hsps will be suitable candidates for immune therapy in chronic arthritis. In addition, treatment with Hsp60 or its peptides can modulate the progression of autoimmune diabetes. Vaccination of non-obese diabetic (NOD) mice with peptides of Hsp60 successfully inhibits the development of spontaneous diabetes (Elias et al. 1997, Bockova et al. 1997). A double-blind, phase II clinical trial found that type 1 diabetes in humans is also susceptible to immunomodulation by p277 peptide of Hsp60 (Raz et al. 2001). The administration of p277 preserves the endogenous levels of C-peptide and is associated with lower requirements of exogenous insulin, revealing the suppression of $\beta$ cell destruction. Inflammatory bowel diseases (IBDs), such as ulcerative colitis and Crohn's disease, are characterized by chronic relapsing inflammation. Hsps induced by hyperthermia prevent leukotriene B4 production, subsequent neutrophil infiltration, epithelial damage, and alterations in tachykinergic control of smooth muscle in an experimental IBD (Goldhill et al. 1999).

\section{Ischemia/reperfusion injury}

Ischemia/reperfusion (I/R) injury is widely recognized as a significant source of morbidity and mortality in a number of clinical situations such as transplantation, trauma, liver, lung, or bowel resection and haemorrhagic shock. A hallmark of $I / R$ is the production of reactive oxygen species (ROS) during the reperfusion phase and it is thought that the production of ROS mediates much of the post-ischemic tissue injury by causing direct cellular damage and/or acting as second messengers in the activation of cellular responses controlling cell death and inflammation. Inflammatory response such as lymphocyte activation, neutrophil infiltration, cytokine release and fibrosis exists in both the 
acute and chronic phases of I/R injuries. Hsps are highly inducible by I/R injury through the activation of HSFs by ischemia (Tacchini et al. 1997). Heme oxygenases (HO)-1 or Hsp32 is upregulated with $\mathrm{I} / \mathrm{R}$ and is thought to be not just anti-oxidative, but also a complex immunomodulator protecting against inflammation in I/R injury (Katori et al. 2002a, 2002b). Interestingly, the expression of Hsp40 and Hsp70 increases during lung rejection in human pulmonary allografts (Rizzo et al. 1998), and elevated levels of Hsp70 correlates with the improved pulmonary function after $\mathrm{I} / \mathrm{R}$ in an isolated rabbit lung model (Long et al. 2003). The cytoprotective effects of Hsps have also been found in $1 / R$ injury in brain, liver, kidney and surgical flap (Plumier et al. 1997, Currie et al. 2000, Uchinami et al. 2002, Wagner et al. 2003, .Rucker et al. 2001).

\section{Cardiovascular diseases}

Heat shock proteins are expressed in the cardiovascular system and appear to have a beneficial role. Currie et al. (1988) reported that whole body heat shock in rats is associated with improvement of cardiac functional recovery after global ischemia and these findings are correlated with significantly increased cardiac Hsp70. Transgenic mice expressing high level constitutive expression of the human inducible $\mathrm{Hsp} 70$ demonstrate the direct role of $\mathrm{Hsp} 70$ in the protection of the myocardium from ischemia and reperfusion injury (Plumier et al. 1995). In addition, heat shock treatment and the concommitant high levels of Hsp70 and Hsp27 and their phosphorylated isoforms protect against angiotensin (Ang) II-induced hypertension and inflammation in heart and aorta (Chen et al. 2004a, 2004b). Heat shock proteins have a role in the treatment of atherosclerosis. Using mucosal administration of Hsp65 Maron et al. (2002) vaccinated low-density lipoprotein receptor deficient (LDL-/-) mice to reduce the inflammatory process, hence provided a new immunologic approach for the treatment of atherosclerosis.

\section{Other inflammatory diseases}

There is also evidence for Hsps having a role in various other models of inflammation. Hsp25, Hsp32, Hsp47, and Hsp70 have been demonstrated to play an anti-inflammation role in some chemicalinduced diseases such as acetic acid-induced gastric ulcer (Guo et al. 2002), thioacetamide-induced liver disease (Zborek et al. 2002) and carrageenin-induced pleurisy (lanaro et al. 2001). Upregulation of Hsp70 also reduces inflammation in asthma and the acute respiratory distress syndrome (Bertorelli et al. 1998, Weiss et al. 2002). Thus Hsps are associated with inflammation. 


\section{MECHANISMS OF ANTI-INFLAMMATION REGULATION OF HSPS}

\section{Extra-cellular mechanisms: autoantigen role of Hsps}

Hsps are now known to be strongly immunogenic despite their high level of evolutionary conservation (van Eden et al. 2003). While Hsps are intracellular proteins, they are also expressed on the cell surface (van Eden 2000). Most self-hsp cross-reactive $T$ cells are also IL-10 producing regulatory T cells (van Eden et al. 2003). Three mechanisms of anti-inflammatory $\mathrm{T}$ cell induction by Hsps have been proposed (Van Eden et al. 2003): (1) Mucosal tolerance: Hsp reactive T cells recognize microbial Hsp epitopes in the gut lymphoid tissue and develop a tolerance when confronted with self-Hsps expressed elsewhere in the body. (2) Altered peptide ligands regulation: Microbial-Hsp reactive T cells perceive self-Hsp homologs as partial agonists or altered peptide ligands and redirect pro-inflammatory (Th1) T cell response to regulatory Th2 response. (3) Anergy: The ubiquitous low level of Hsp is also expressed on non-professional antigen presenting cells that lack the costimulatory molecules needed to induce a $T$ cell response. This constitutive Hsp expression in non-professional antigen presenting cells in the absence of proper co-stimulation drives self-Hsp recognizing $T$ cells into a state of anergy. Such "anergic" T cells inhibit the proliferation and activation of other $\mathrm{T}$ cells when confronted with professional or activated antigen presenting cells.

\section{Intra-cellular mechanisms: crosstalk between Hsps and cell signaling transduction pathways}

Recently, several studies show that Hsps interact with some intracellular signaling transduction pathways involved in inflammation. NF- $\kappa B$ is a pivotal transcription factor that functions to control the transcription of a variety of pro-inflammatory genes, including cytokines, growth factors, adhesion molecules, immunoreceptors and acute-phase proteins. The HS response and NF- $\mathrm{HB}$ signaling pathway are two fundamental cellular processes. The interaction between Hsps and HS response, and NF-KB pathway effect various levels of the pathway (Figure 1). Our laboratory (Chen et al. 2004a, 2004b) and others (Wong et al. 1997, Pritts et al. 2000, Yoo et al. 2000) have found that heat shock suppresses NF- $\kappa \mathrm{B}$ activation by inhibiting the phosphorylation and degradation of its inhibitor, I $\mathrm{\kappa B}-\alpha$. In fact Hsp70 through its molecular chaperone activity interacts and forms complexes with $I_{\kappa} \mathrm{B}-\alpha$ and is

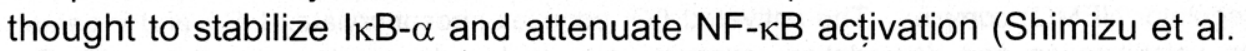
2002). Hsp70 may also directly interact or chaperone NF-kB, as a partial substitute for $I_{\kappa B}$ (Guzhova et al. 1997). Alternatively, the human IKB- $\alpha$ gene promoter region contains a contiguous 20 bp segment that matches with the heat shock element in the promoter region of Hsp genes (Wong et al. 1997). After heat shock (HS), both $I_{\kappa B} \mathrm{~B}-\alpha$ and another 
NF- $\kappa B$ inhibitor $I_{\kappa} B-\beta$ are expressed and, thus, can be regarded as heat shock proteins (Wong et al. 1997, 1999, Stasiolek et al. 2000). HS inhibits radiation-induced activation of $I_{\kappa} B$ kinase (IKK) (Curry et al. 1999, Yoo et al. 2000) and appears to increase intracellular phosphatase activity (Malhotra \& Wong 2002). Consistent with this, HS decreases the cytoplasmic level of IKK- $\alpha$ (Chen et al. 2004b) and is correlated with the higher expression of Hsp70, Hsp27 and their phosphorylated isoforms. Interestingly, Park et al. (2003) found that Hsp27 interacts directly with IKK- $\alpha$ and IKK- $\beta$ in down-regulation of TNF- $\alpha$ induced NF- $\kappa B$ activation via its phosphorylation. Hsp70/HS have also been found to suppress other proinflammatory pathways such as JNK and p38 (He et al. 2000, Wang et al. 2002) and it is likely that HS and Hsps will suppress proinflammatory and increase anti-inflammatory transcription factors.

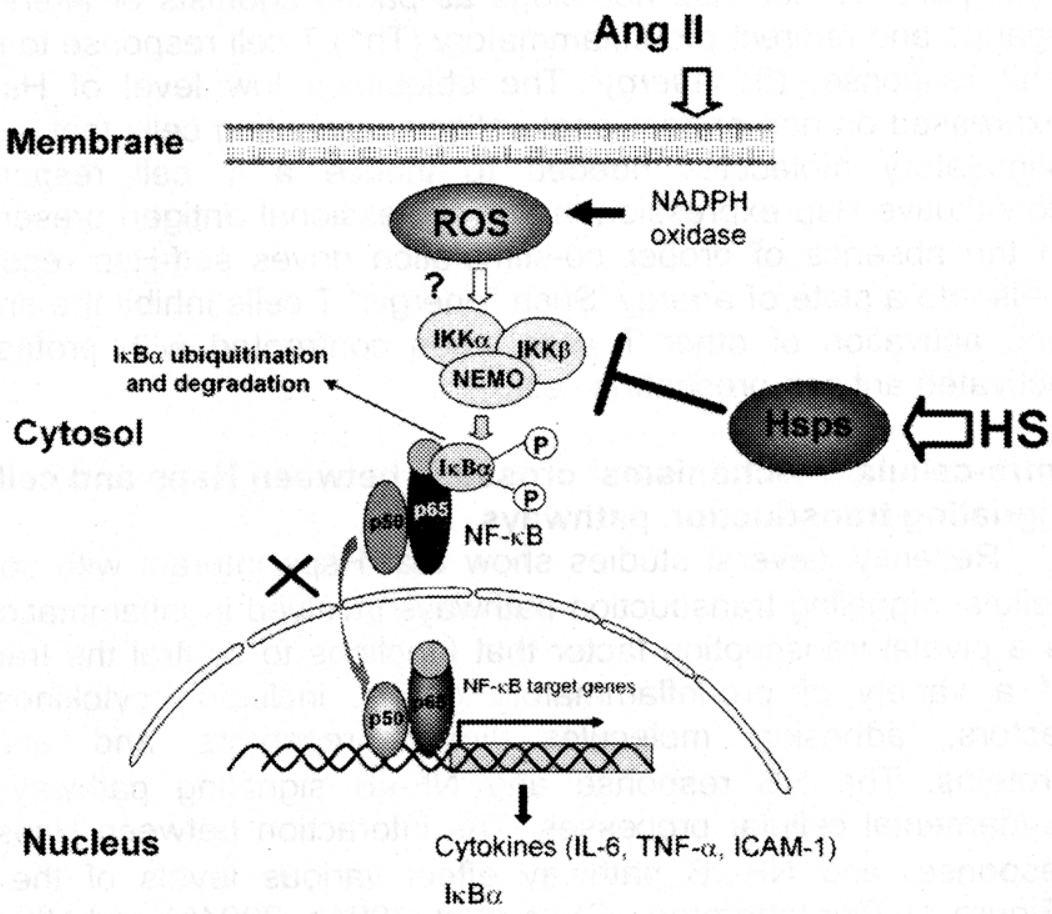

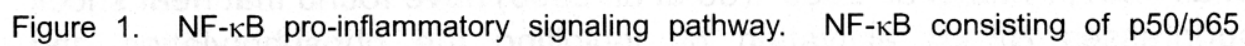
subunits is normally resident in the cytosol and is maintained in an inactive form by its inhibitor I $\mathrm{B} \mathrm{B} \alpha$. Angiotensin II (Ang II) stimulates NADPH oxidase to release reactive oxygen species (ROS) that are thought to activate the IKB kinase (IKK $\alpha$, IKK $\beta$, and their regulator NEMO) complex. The activated IKK complex phosphorylates I $\mathrm{KB} \alpha$ and initiates its ubiquitination and degradation, exposing the nuclear localization signal on NF- $\mathrm{KB}$.. Freed $\mathrm{NF}-\kappa \mathrm{B}$ is translocated to the nucleus and binds to the promoter region of genes expressing pro-inflammatory cytokines such as Interleukin-6 (IL-6), tumor necrosis factor- $\alpha$ $(T N F-\alpha)$, intercellular adhesion molecule-1 (ICAM-1) and $I_{\kappa} B \alpha$. Heat shock (HS) strongly elevates the expression of several heat shock proteins that interact with the IKK complex to suppress its activation. 


\section{PARADOXES OF HSPS AND PERSPECTIVES}

As an alternative to controlling inflammation by using anti-cytokine treatments that are currently less than fully effective at controlling the many cytokines, regulation of Hsps may be a novel and more effective approach to anti-inflammatory therapy. In fact, many of the current widely used nonsteroid anti-inflammatory drugs (NSAIDs) induce HSF activation and increase the expression of Hsps (Polla et al. 1998). Paradoxically, not all aspects of the heat shock response are protective. Firstly, some Hsps, and especially the Hsp60 family have been found to induce macrophages to secrete pro-inflammatory mediators such as TNF- $\alpha$, IL-6, IL-12, and nitric oxide (Ohashi et al. 2000, Flohe et al. 2003). Contradictory pro-inflammatory and anti-inflammatory effects of Hsp60 in various cell types may be because Hsp60 works as a ligand both for toll-like receptor-4 (TLR-4) and TLR-2 in T cells and B cells. Hsp60 and its fragments can regulate the physiology of inflammation itself by acting as ligands for TLR-2 (Zanin-Zhorov et al. 2003), while Hsp60 might elicit a potent pro-inflammatory response through TLR-4 signaling (Ohashi et al. 2000). Whether Hsp60 is a "smart" molecular switch in the regulation of inflammation requires further investigation. Secondly, HS and expression of Hsps can have contradictory effects such as being benefical before a pro-inflammatory stimulus (e.g., NF-кB activation), compared to cytotoxic effects after a pro-inflammatory stimulus (DeMeester et al. 2001). Such paradoxical effects in HS and NF- $\kappa B$ regulation may be involved in critical illnesses such as multiple organ dysfunction. Thirdly, sustained inflammation in some chronic diseases may be caused by the undesired prolonged survival of proinflammatory cells. The cytoprotective effects of Hsps during apoptosis, although beneficial in other pathologic conditions, may contribute to chronic inflammation. The increase in HSF activity and subsequent Hsp production may differentially influence three mitogen-activated protein kinase (MAPK) pathways under various stressful conditions (Malago et al. 2002). Hsps protect against apoptosis via ERK1/2 MAPK pathway, while they suppress inflammation through JNK and p38 MAPK activity. However, all three MAPK pathways can be activated at one time. A better understanding of interactions between Hsps and regulators of apoptosis and inflammation and how these interactions can be modulated by the levels of the Hsps needs to be investigated as an alternative approach for controlling inflammatory diseases.

Acknowledgements. This work was funded by the Heart and Stroke Foundation of New Brunswick and the Canadian Institute for Health Research in partnership with the Nova Scotia Health Research Foundation. Yu Chen was a Killam scholar (2000-2003) and is a recipient of a scholarship from Nova Scotia Health Research Foundation (2003-2005). 


\section{REFERENCES}

Agnello D, Scanziani E, Di GM, Leoni F and 5 others (2002) Preventive administration of Mycobacterium tuberculosis $10-\mathrm{kDa}$ heat shock protein (hsp10) suppresses adjuvant arthritis in Lewis rats. Int Immunopharmacol 2:463-474

Beere HM (2001) Stressed to death: regulation of apoptotic signaling pathways by the heat shock proteins. Sci STKE 31:RE1

Bertorelli G, Bocchino V, Zhuo X, Chetta A, Del Donno M, Foresi A, Testi R, Olivieri D (1998) Heat shock protein 70 upregulation is related to HLA-DR expression in bronchial asthma. Effects of inhaled glucocorticoids. Clin Exp Allergy 28:551-560

Bhagat L, Singh VP, Hietaranta AJ, Agrawal S, Steer ML, Saluja AK (2000) Heat shock protein 70 prevents secretagogue-induced cell injury in the pancreas by preventing intracellular trypsinogen activation. J Clin Invest 106:81-89

Bockova J, Elias D, Cohen IR (1997) Treatment of NOD diabetes with a novel peptide of the hsp60 molecule induces Th2-type antibodies. J Autoimmun 10:323-329

Calandra T, Bochud PY, Heumann D (2002) Cytokines in septic shock. Curr Clin Top Infect Dis 22:1-23

Chen Y, Arrigo AP, Currie RW (2004b) Heat shock treatment suppresses angiotensin II-induced activation of IKK/NF-KB pathway and heart inflammation. Am J Physiol 287: $\mathrm{H} 1104-\mathrm{H} 1114$

Chen Y, Ross BM, Currie RW (2004a) Heat shock treatment protects against angiotensin II-induced hypertension and inflammation in aorta. Cell Stress Chaperones 9:99-107

Cohen IR, Efroni S (2003) Inflammation and vaccination: Cause and cure for Type 1 diabetes. In: Raz I, Skyler JS, Shafir E (ed) Diabetes: From research to diagnosis and treatment. Martin Dunitz, London, p 223-233

Currie RW, Plumier JC (1998) The heat shock response and tissue protection. In: Baxter GF, Yellon DM (ed) Delayed preconditioning and adaptive cardioprotection. Kluwer Academic Publishers, Dordrecht, The Netherlands, $p$ 135-153

Currie RW, Ellison JA, White RF, Feuerstein GZ, Wang X, Barone FC (2000) Benign focal ischemic preconditioning induces neuronal Hsp70 and prolonged astrogliosis with expression of Hsp27. Brain Res 863:169-181

Currie RW, Karmazyn M, Kloc M, Mailer K (1988) Heat-shock response is associated with enhanced postischemic ventricular recovery. Circ Res 63:543-549

Curry HA, Clemens RA, Shah S, Bradbury CM, Botero A, Goswami P, Gius D (1999) Heat shock inhibits radiation-induced activation of NF-kappaB via inhibition of I-kappaB kinase. J Biol Chem 274:23061-23067

DeMeester SL, Buchman TG, Cobb JP (2001) The heat shock paradox: Does NF-kappaB determine cell fate? FASEB J 15:270-274

Ding XZ, Fernandez-Prada CM, Bhattacharjee AK, Hoover DL (2001) Overexpression of hsp-70 inhibits bacterial lipopolysaccharide-induced production of cytokines in human monocyte-derived macrophages. Cytokine 16:210-219

Dirckx JH (2001) Stedman's concise medical dictionary for the health professions: Illustrated $4^{\text {th }}$ ed. Lippincott Williams \& Wilkins, Baltimore 
Eaves-Pyles T, Wong HR, Alexander JW (2000) Sodium arsenite induces the stress response in the gut and decreases bacterial translocation in a burned mouse model with gut-derived sepsis. Shock 13:314-319

Elias D, Meilin A, Ablamunits V, Birk OS, Carmi P, Konen-Waisman S, Cohen IR (1997) Hsp60 peptide therapy of NOD mouse diabetes induces a Th2 cytokine burst and downregulates autoimmunity to various beta-cell antigens. Diabetes 46:758-764

Ellis RJ, van der Vies SM (1991) Molecular chaperones. Annu Rev Biochem 60:321-347

Flohe SB, Bruggemann J, Lendemans S, Nikulina M, Meierhoff G, Flohe S, Kolb H (2003) Human heat shock protein 60 induces maturation of dendritic cells versus a Th1-promoting phenotype. J Immunol 170:2340-2348

Florey L (1970) General pathology. $4^{\text {th }}$ ed. Lloyd-Luke medical books, London

Goldhill JM, Stojadinovic A, Kiang J, Smallridge R, Shea-Donohue T (1999) Hyperthermia prevents functional, histological and biochemical abnormalities induced during ileitis. Neurogastroenterol Motil 11:69-76

Guo JS, Cho CH, Wang JY, Koo MW (2002) Expression and immunolocalization of heat shock proteins in the healing of gastric ulcers in rats. Scand J Gastroenterol 37:17-22

Guzhova IV, Darieva ZA, Melo AR, Margulis BA (1997) Major stress protein Hsp70 interacts with NF-kB regulatory complex in human T-lymphoma cells. Cell Stress Chaperones 2:132-139

HartI FU (1996) Molecular chaperones in cellular protein folding. Nature 381 : 571-579

He H, Chen C, Xie Y, Asea A, Calderwood SK (2000) HSP70 and heat shock factor 1 cooperate to repress Ras-induced transcriptional activation of the cfos gene. Cell Stress Chaperones 5:406-411

lanaro A, Ialenti A, Maffia P, Pisano B, Di Rosa M (2001) HSF1/hsp72 pathway as an endogenous anti-inflammatory system. FEBS Lett 499:239-244

. Katori M, Anselmo DM, Busuttil RW, Kupiec-Weglinski JW (2002a) A novel strategy against ischemia and reperfusion injury: Cytoprotection with heme oxygenase system. Transpl Immunol 9:227-233

Katori M, Busuttil RW, Kupiec-Weglinski JW (2002b) Heme oxygenase-1 system in organ transplantation. Transplantation 74:905-912

Long SM, Laubach VE, Tribble CG, Kaza AK, Fiser SM, Cassada DC, Kern JA, Kron IL (2003) Pyrrolidine dithiocarbamate reduces lung reperfusion injury. J Surg Res 112:12-18

Malago JJ, Koninkx JF, van Dijk JE (2002) The heat shock response and cytoprotection of the intestinal epithelium. Cell Stress Chaperones 7:191-199

Malhotra V, Woing HR (2002) Interactions between the heat shock response and the nuclear factor-kappaB signaling pathway. Crit Care Med 30(Supp):S89S95

Maron R, Sukhova G, Faria AM, Hoffmann E, Mach F, Libby P, Weiner HL (2002) Mucosal administration of heat shock protein-65 decreases atherosclerosis and inflammation in aortic arch of low-density lipoprotein receptor-deficient mice. Circulation 106:1708-1715

Mosmann TR, Sad S (1996) The expanding universe of T-cell subsets: Th1, Th2 and more. Immunol Today 17:138-146

Ohashi K, Burkart V, Flohe S, Kolb H (2000) Cutting edge: Heat shock protein 60 is a putative endogenous ligand of the toll-like receptor-4 complex. J Immunol 164:558-561 
Paidas CN, Mooney ML, Theodorakis NG, De Maio A (2002) Accelerated recovery after endotoxic challenge in heat shock-pretreated mice. Am J Physiol 282:R1374-R1381

Park KJ, Gaynor RB, Kwak YT (2003) Heat shock protein 27 association with the I kappa B kinase complex regulates tumor necrosis factor alpha-induced NF-kappa B activation. J Biol Chem 278:35272-35278

Plumier JC, Krueger AM, Currie RW, Kontoyiannis D, Kollias G, Pagoulatos GN (1997) Transgenic mice expressing the human inducible Hsp70 have hippocampal neurons resistant to ischemic injury. Cell Stress Chaperones 2:162-167

Plumier JC, Ross BM, Currie RW, Angelidis CE, Kazlaris H, Kollias G, Pagoulatos GN (1995) Transgenic mice expressing the human heat shock protein 70 have improved post-ischemic myocardial recovery. J Clin Invest 95:1854-1860

Polla BS, Bachelet M (1998) Stress proteins in inflammation. Ann N Y Acad Sci 851:75-85

Prakken BJ, Roord S, Ronaghy A, Wauben M, Albani S, van Eden W (2003) Heat shock protein 60 and adjuvant arthritis: A model for $T$ cell regulation in human arthritis. Springer Semin Immunopathol 25:47-463

Prakken BJ, Roord S, van Kooten PJ,.Wagenaar JP, van Eden W, Albani S, Wauben MH, (2002) Inhibition of adjuvant-induced arthritis by interleukin-10driven regulatory cells induced via nasal administration of a peptide analog of an arthritis-related heat-shock protein $60 \mathrm{~T}$ cell epitope. Arthritis Rheum 46:1937-1946

Pritts TA, Wang Q, Sun X, Moon MR, Fischer DR, Fischer JE, Wong HR, Hasselgren PO (2000) Induction of the stress response in vivo decreases nuclear factor-kappa B activity in jejunal mucosa of endotoxemic mice. Arch Surg 135:860-866

Puga Yung GL, Le TD, Roord S, Prakken B, Albani S (2003) Heat shock proteins (HSP) for immunotherapy of rheumatoid arthritis (RA). Inflamm Res $52: 443-451$

Raz I, Elias D, Avron A, Tamir M, Metzger M, Cohen IR (2001) Beta-cell function in new-onset type 1 diabetes and immunomodulation with a heatshock protein peptide (DiaPep277): a randomised, double-blind, phase II trial. Lancet 58:1749-1753

Ritossa F (1962) A new puffing pattern induced by temperature shock and DNP in Drosophila. Experientia 18:571-573

Rizzo M, Alevy YG, Sundaresan S, Lynch J, Trulock EP, Cooper JD, Patterson GA, Mohanakumar T (1998) Increased expression of HDJ-2 (heat shock protein 40 ) and heat shock protein 70 in biopsy specimens of transplanted human lungs. J Heart Lung Transplant 17:241-249

Rogalla T, Ehrnsperger M, Preville X, Kotlyarov A and 7 others (1999) Regulation of Hsp27 oligomerization, chaperone function, and protective activity against oxidative stress/tumor necrosis factor alpha by phosphorylation. J Biol Chem 274: 18947-18956

Rucker M, Schafer T, Roesken F, Spitzer WJ, Bauer M, Mengere MD (2001) Reduction of inflammatory response in composite flap transfer by local stress conditioning-induced heat-shock protein 32 . Surgery 129:292-301

Santoro MG (1994) Heat shock proteins and virus replication: Hsp70s as mediators of the antiviral effects of prostaglandins. Experientia 50:1039-1047 
Santoro MG (1997) Antiviral activity of cyclopentenone prostanoids. Trends Microbiol 5:276-281

Shimizu M, Tamamori-Adachi M, Arai H, Tabuchi N, Tanaka H, Sunamori M (2002) Lipopolysaccharide pretreatment attenuates myocardial infarct size: A possible mechanism involving heat shock protein 70-inhibitory kappaBalpha complex and attenuation of nuclear factor kappaB. J Thorac Cardiovasc Surg 124:933-941

Stasiolek M, Gavrilyuk V, Sharp A, Horvath P, Selmaj K, Feinstein DL (2000) Inhibitory and stimulatory effects of lactacystin on expression of nitric oxide synthase type 2 in brain glial cells. The role of Ikappa B-beta. J Biol Chem 275:24847-24856

Tacchini L, Radice L, Pogliaghi G, Bernelli-Zazzera A (1997) Differential activation of heat shock and nuclear factor kappaB transcription factors in postischemic reperfused rat liver. Hepatology 26:186-191

Tissieres A, Mitchell HS, Tracy U (1974) Protein synthesis in salivary glands of Drosophila melanogaster. Relationship to chromosome puffs. J Mol Biol 84:389-398

Uchinami H, Yamamoto Y, Kume M, Yonezawa K and 5 others (2002) Effect of heat shock preconditioning on NF-kappaB/l-kappaB pathway during I/R injury of the rat liver. Am J Physiol 282:G962-G971

van Eden W (2000) Stress proteins as targets for anti-inflammatory therapies. Drug Discov Today 5:115-120

van Eden W, Koets A, van Kooten P, Prakken B, van der Zee R (2003) Immunopotentiating heat shock proteins: negotiators between innate danger and control of autoimmunity. Vaccine 21:897-901

Vreugdenhil HA, Haitsma JJ, Jansen KJ, Zijlstra J and 5 others (2003) Ventilator-induced heat shock protein 70 and cytokine mRNA expression in a model of lipopolysaccharide-induced lung inflammation. Intensive Care Med 29:915-922

Wagner M, Cadetg P, Ruf R, Mazzucchelli L, Ferrari P, Redaelli CA (2003) Heme oxygenase-1 attenuates ischemia/reperfusion-induced apoptosis and improves survival in rat renal allografts. Kidney Int 63:1564-1573

Wang Y, Li C, Wang X, Zhang J, Chang Z (2002) Heat shock response inhibits IL-18 expression through the JNK pathway in murine peritoneal macrophages. Biochem Biophys Res Commun 296:742-748

Weiss YG, Maloyan A, Tazelaar J, Raj N, Deutschman CS (2002) Adenoviral transfer of HSP-70 into pulmonary epithelium ameliorates experimental acute respiratory distress syndrome. J Clin Invest 110:801-806

Wendling U, Paul L, van der Zee R, Prakken B, Singh M, van Eden W (2000) A conserved mycobacterial heat shock protein (hsp) 70 sequence prevents adjuvant arthritis upon nasal administration and induces IL-10-producing $T$ cells that cross-react with the mammalian self-hsp70 homologue. J Immunol 164:2711-2717

Wick G, Perschinka H, Millonig G (2001) Atherosclerosis as an autoimmue disease: An update. Trends Immunol 22:665-669

Wong HR, Ryan M, Wispe JR (1997) Stress response decreases NF-kappaB nuclear translocation and increases l-kappaBalpha expression in A549 cells.

J Clin Invest 99:2423-2428

Wong HR, Ryan MA, Menendez IY, Wispe JR (1999) Heat shock activates the I-kappaBalpha promoter and increases I-kappaBalpha mRNA expression. Cell Stress Chaperones 4:1-7 
Xiao X, Zuo X, Davis AA, McMillan DR, Curry BB, Richardson JA, Benjamin IJ (1999) HSF1 is required for extra-embryonic development, postnatal growth and protection during inflammatory responses in mice. EMBO J 18:5943-5952

Yoo CG, Lee S, Lee CT, Kim YW, Han SK, Shim YS (2000) Anti-inflammatory effect of heat shock protein induction is related to stabilization of I kappa B alpha through preventing I kappa B kinase activation in respiratory epithelial cells. J Immunol 164:5416-5423

Yoshikai Y (1998) The roles of heat shock proteins in host defense against bacterial infection. Rinsho Byori 46:564-573

Zanin-Zhorov A, Nussbaum G, Franitza S, Cohen IR, Lider O (2003) T cells respond to heat shock protein 60 via TLR2: activation of adhesion and inhibition of chemokine receptors. FASEB J 17:1567-1569

Zborek A, Malusecka E, Krzyowska-Gruca S, Wysocka A, Krawczyk Z (2002) Immunohistochemical studies on the expression pattern of molecular chaperones HSC70 and HSP25 and cell cycle-related proteins cyclin D1 and PCNA in rat liver after thioacetamide intoxication. Histochem Cell Biol 188:311-319 